\title{
Embryonic exposure to oestrogen causes eggshell thinning and altered shell gland carbonic anhydrase expression in the domestic hen
}

\author{
C Berg, A Blomqvist ${ }^{1}$, L Holm ${ }^{1}$, I Brandt, B Brunström and Y Ridderstråle ${ }^{1}$ \\ Department of Environmental Toxicology, Uppsala University, Norbyvägen 18 A, 75336 Uppsala, Sweden and \\ ${ }^{1}$ Department of Anatomy and Physiology, Swedish University of Agricultural Sciences, Box 7045, 75007 Uppsala, \\ Sweden
}

Correspondence should be addressed to C Berg; Email: Cecilia.Berg@ebc.uu.se

\begin{abstract}
Eggshell thinning among wild birds has been an environmental concern for almost half a century. Although the mechanisms for contaminant-induced eggshell thinning are not fully understood, it is generally conceived to originate from exposure of the laying adult female. Here we show that eggshell thinning in the domestic hen is induced by embryonic exposure to the synthetic oestrogen ethynyloestradiol. Previously we reported that exposure of quail embryos to ethynyloestradiol caused histological changes and disrupted localization of carbonic anhydrase in the shell gland in the adult birds, implying a functional disturbance in the shell gland. The objective of this study was to examine whether in ovo exposure to ethynyloestradiol can affect eggshell formation and quality in the domestic hen. When examined at 32 weeks of age, hens exposed to ethynyloestradiol in ovo $(20 \mathrm{ng} / \mathrm{g} \mathrm{egg})$ produced eggs with thinner eggshells and reduced strength (measured as resistance to deformation) compared with the controls. These changes remained 14 weeks later, confirming a persistent lesion. Ethynyloestradiol also caused a decrease in the number of shell gland capillaries and in the frequency of shell gland capillaries with carbonic anhydrase activity. These data suggested that a disrupted carbonic anhydrase expression was involved in the mechanism for the oestrogen-induced eggshell thinning found in this study. The results support our hypothesis that eggshell thinning in avian wildlife can result from a structural and functional malformation in the shell gland, induced by xeno-oestrogen exposure during embryonic development.

Reproduction (2004) 128 455-461
\end{abstract}

\section{Introduction}

Reproductive failure due to eggshell thinning is one of the most serious ecotoxicological effects that have afflicted avian wildlife. It is therefore intriguing that, in spite of numerous attempts to explain contaminant-induced eggshell thinning, the underlying mechanism of action still remains to be clarified. During the 1950s, 1960s and 1970s, population decline consequent to eggshell thinning was observed in several bird species in Europe and North America. 2,2-bis(chlorophenyl)-1,1,1-trichloethane (DDT) and its persistent metabolite 2,2-bis(4-chlorophenyl)-1,1dichloroethane $\left(p, p^{\prime}\right.$-DDE) were pointed out as the main culprits (Ratcliffe 1967, 1970, Hickey \& Anderson 1968, Cooke 1973, Faber \& Hickey 1973), although also other chemicals have been associated with decreased shell quality. Several explanations for DDT/DDE-induced eggshell thinning have been proposed, all based on the assumption that pollutant-induced eggshell thinning is caused by exposure of the adult bird. According to the most current hypothesis, $p, p^{\prime}$-DDE exposure of the adult bird inhibits prostaglandin synthesis in the shell gland mucosa and, as a consequence, calcium and bicarbonate transport across the mucosa is reduced (Lundholm 1993, 1997).

The avian eggshell consists mainly of calcium carbonate. The carbonate ions are formed from metabolic $\mathrm{CO}_{2}$. The first step in the carbonate ion formation, i.e. $\mathrm{CO}_{2}+$ $\mathrm{H}_{2} \mathrm{O} \leftrightarrow \mathrm{H}^{+}+\mathrm{HCO}_{3}^{-}$, is catalyzed by carbonic anhydrase (CA), an enzyme family consisting of at least 14 different isozymes (reviewed in Chegwidden \& Carter 2000). We have previously reported that embryonic exposure to the synthetic oestrogen ethynyloestradiol $\left(\mathrm{EE}_{2}\right)$ results in disrupted expression of CA as well as anatomical and histological alterations in the shell gland in quail (Berg et al. 2001, Holm et al. 2001). These findings led us to propose that eggshell thinning could reflect a functional malformation in the shell gland induced in ovo, rather than being caused solely by exposure of the adult egg-laying female. 
The objective of the present study was to test this hypothesis in domestic hens. Following exposure to $\mathrm{EE}_{2}$ in ovo, chicks were raised to adult age. Egg production of the adult females was determined and eggshell quality was measured. Oviduct histology and localization of CA in the oviduct were examined.

\section{Materials and Methods}

Fertilized eggs from White Leghorn chickens (strain SLU13; University breeder flock, Uppsala, Sweden) were incubated at $37.2-37.7^{\circ} \mathrm{C}$ and turned every third hour. Eggs, incubated for 4 days, were injected with $\mathrm{EE}_{2}$ (Sigma Chemical Co., St Louis, MO, USA) into the yolk via a small hole drilled at the blunt end of the egg. The $\mathrm{EE}_{2}$ was dissolved in a mixture of peanut oil and lecithin from which an emulsion in water was prepared and used as vehicle (Brunström \& Örberg 1982, Brunström \& Darnerud 1983). The doses were 2, 7 or $20 \mathrm{ng} \mathrm{EE}_{2} / \mathrm{g}$ egg, referred to as low (LD), intermediate (ID) and high dose (HD). Control eggs were given vehicle only. Yolk injection was used as a route for administration in order to simulate the way wild birds are exposed to lipophilic pollutants during development. The injection volume was $100 \mu \mathrm{l}$. After injection, the hole was sealed with paraffin wax and the eggs were returned to the incubator. On day 19 of incubation, the eggs were placed in a hatcher at $37.0^{\circ} \mathrm{C}$ and $70 \%$ relative humidity. Hatchlings were sexed by cloacal inspection on day 22. Male chicks were killed immediately whereas female chicks were wing banded and vaccinated against Marek's disease. The chicks were reared in groups for 16 weeks and were then moved to single-hen cages. During the rearing and growing periods, the birds were fed commercial starter and grower diets. The birds were raised in $8 \mathrm{~h}$ light/16 h dark until 15 weeks of age, thereafter light was gradually increased by $20 \mathrm{~min} /$ week until $16 \mathrm{~h}$ light $/ 8 \mathrm{~h}$ light was attained. The chicks were weighed once every second week until 12 weeks of age, thereafter at weeks 20 and 37. The number of injected and hatched eggs, the number of female chicks and the number of laying hens in each treatment group are given in Table 1 . The study was approved by the Uppsala Local Ethics Committee.

Table 1 Number of injected and hatched eggs, number of hatched females, mortality and number of laying females after in ovo exposure to $\mathrm{EE}_{2}$.

\begin{tabular}{lccrr}
\hline & Control & LD & ID & HD \\
\hline Total no. of injected eggs & 40 & 37 & 38 & 40 \\
Hatched eggs & 29 & 23 & 28 & 29 \\
Hatched female chicks & 12 & 12 & 16 & 12 \\
Mortality $^{\text {Laying hens }}{ }^{\mathrm{a}}$ & 2 & 3 & 1 & 1 \\
Laying hens $^{\mathrm{b}}$ & 10 & 9 & 15 & 11 \\
\hline
\end{tabular}

a at 32 weeks of age.

b at 46 weeks of age.

\section{Egg and eggshell measurements}

Onset of lay and total number of eggs were recorded for each bird. Egg and shell characteristics were measured at two time-points during the egg-laying period, when the hens were 32 and 46 weeks old. For these measurements, eggs were collected each morning for 5 consecutive days. The mean values of egg and shell characteristics were consequently derived from measurements on up to five eggs/hen. The mean values for each treatment group given in Tables 2 and 3 were calculated from the mean values for each bird.

Egg length and width were measured using digital Vernier callipers. Shell strength was determined as nondestructive deformation (Hamilton 1982) using an apparatus constructed for this purpose (Örberg 1990). In brief, a rod is lowered until it rests on the upper surface of the egg. A weight $(437.5 \mathrm{~g})$ is then applied to the top of the rod and deformation of the shell (in $\mu \mathrm{m}$ ) is shown on a gauge. Deformation was measured at three points approximately $120^{\circ}$ apart along the equator of the egg. Three measurements/point were performed (i.e. nine measurements/egg) and a mean value was calculated for each egg.

The eggs were carefully cracked, the shell rinsed clean from albumen with distilled water, and dried overnight at $120^{\circ} \mathrm{C}$. Shell weight (with shell membranes) was recorded. Shell membranes were removed by boiling the shells in $2.5 \%(\mathrm{w} / \mathrm{v}) \mathrm{NaOH}$ for $8 \mathrm{~min}$, rinsing in distilled water and drying overnight at $120^{\circ} \mathrm{C}$. Shell thickness was measured with a digital micrometer (Mitutoyo Absolute, No. 7360; Mitutoyo Corp., Stockholm, Sweden) on three shell pieces taken along the equator.

\section{CA histochemistry}

At 47 weeks of age, the birds were killed by an intravenous injection of pentobarbital sodium. Oviducts were rapidly removed, measured, cut open lengthwise and fixed in 5\% (w/v) paraformaldehyde in phosphate buffer $(0.067 \mathrm{~mol} / \mathrm{l}, \mathrm{pH} 7.2)$ for $24 \mathrm{~h}$ at $4{ }^{\circ} \mathrm{C}$. Three transverse slices ( $2 \mathrm{~mm}$ thick) were cut from each of the following regions: infundibulum, magnum, isthmus and uterus. From the uterovaginal junction (UVJ), tissue slices were cut lengthwise.

Localization of CA activity was performed according to Ridderstråle's histochemical method (Ridderstråle 1976, 1991). Following dehydration in gradients of ethanol, the samples were embedded in a water soluble resin (Leica historesin, Heidelberg, Germany). Sections (2 $\mu \mathrm{m})$ were cut on a microtome (Leica RM 2165, Leica Instruments $\mathrm{GmbH}$, Heidelberg, Germany) using glass knives. The sections were incubated for $6 \mathrm{~min}$ floating on the incubation medium containing $3.5 \mathrm{mmol} / \mathrm{l} \mathrm{CoSO}_{4}, 53 \mathrm{mmol} / \mathrm{I} \mathrm{H}_{2} \mathrm{SO}_{4}$, $11.7 \mathrm{mmol} / \mathrm{l} \quad \mathrm{KH}_{2} \mathrm{PO}_{4}$ and $157 \mathrm{mmol} / \mathrm{l} \quad \mathrm{NaHCO}_{3}$. After incubation, the sections were rinsed in $0.67 \mathrm{mmol} / \mathrm{l}$ phosphate buffer $(\mathrm{pH} 5.9)$, transferred to $0.5 \%(\mathrm{v} / \mathrm{v})\left(\mathrm{NH}_{4}\right)_{2} \mathrm{~S}$, and finally rinsed in two successive baths with distilled water. The incubation procedure results in a black 
Table 2 Effects of embryonic exposure to $\mathrm{EE}_{2}$ on egg and eggshell characteristics, mean values \pm S.D. (first laying period at 32 weeks of age).

\begin{tabular}{lllll}
\hline Variable & Control $^{\mathrm{a}}$ & LD $^{\mathrm{b}}$ & ID $^{\mathrm{c}}$ & HD $^{\mathrm{d}}$ \\
\hline Shell thickness $(\mathrm{mm})$ & $0.35 \pm 0.03$ & $0.34 \pm 0.01$ & $0.35 \pm 0.03$ & $0.32 \pm 0.03 *$ \\
Shell deformation $(\mu \mathrm{m})$ & $2.19 \pm 0.29$ & $2.24 \pm 0.14$ & $2.25 \pm 0.57$ & $2.68 \pm 0.52 *$ \\
Shell weight $(\mathrm{g})$ & $5.01 \pm 0.45$ & $4.88 \pm 0.23$ & $5.07 \pm 0.53$ & $4.51 \pm 0.6 *$ \\
Egg weight $(\mathrm{g})$ & $52.2 \pm 4.1$ & $51.8 \pm 2.9$ & $53.2 \pm 3.8$ & $50.9 \pm 3.2$ \\
Egg length $(\mathrm{mm})$ & $55.2 \pm 1.2$ & $55.0 \pm 1.1$ & $54.7 \pm 1.5$ & $41.7 \pm 1.1$ \\
Egg width $(\mathrm{mm})$ & $41.0 \pm 1.2$ & $40.9 \pm 0.7$ & $41.7 \pm 1.7$ \\
\hline
\end{tabular}

* Significantly different from controls $(P<0.05)$

${ }^{a} n=10$ birds. Total number of eggs $=43$.

${ }^{\mathrm{b}} n=9$ birds. Total number of eggs $=39$.

${ }^{\mathrm{c}} n=15$ birds. Total number of eggs $=60$.

${ }^{\mathrm{d}} n=11$ birds. Total number of eggs $=47$.

precipitate of cobalt sulphide at sites of active CA. Before mounting, some of the sections were counter-stained with azure blue. Neighbouring sections were stained with haematoxylin-eosin for histological examination.

The specificity of the reaction was checked using the CA inhibitor acetazolamide. Sections were first preincubated in a $10 \mu \mathrm{mol} / \mathrm{l}$ solution of acetazolamide for $30 \mathrm{~min}$ and then incubated as above but with an incubation medium containing $10 \mu \mathrm{mol} / \mathrm{l}$ inhibitor. Sections incubated with the inhibitor contained no significant staining.

\section{Image analysis}

Digital images of CA-stained sections from the shell gland of control birds and birds exposed to $20 \mathrm{ng} \mathrm{EE}_{2} / \mathrm{g}$ egg were taken using a Nikon Microphot-FXA imaging system (Bergström Instrument AB, Stockholm, Sweden). One image of the top of five consecutive mucosal folds in one section/ bird was used. Only tall mucosal folds attached to the underlying muscular layer were chosen. The total number of capillaries $/ \mathrm{mm}^{2}$ of tissue and the frequency of capillaries positive for CA activity were determined using an image analysis software (Easy Image Measurements 2000; Bergström Instrument AB, Stockholm, Sweden). Capillaries were counted only if the entire capillary was located within the picture frame. A capillary was considered CA positive if more than half of its circumference was showing CA activity (black staining). All slides were coded and the analysis of all slides was performed by the same person.
Areas of the images not containing tissue (i.e. shell gland lumen) were excluded.

\section{Statistics}

Student's $t$-test (two-tailed) was used to compare $\mathrm{EE}_{2}$ exposed and control groups with respect to hatchability, body weight, mortality, egg production, egg characteristics and egg shell data. Student's t-test was also used to compare the total amount of capillaries in HD and control birds. The frequency of capillaries positive for CA activity in HD and control birds was compared using Fisher's exact test. $P<0.05$ was considered significant.

\section{Results}

There were no differences between the $\mathrm{EE}_{2}$-exposed groups and the control group regarding hatchability of injected eggs, mortality (Table 1) or body weights. The percentage of hatched eggs was $72.5 \%$ in the control group and $62.2 \%, 73.7 \%$ and $72.5 \%$ in the LD, ID and HD groups respectively. The average body weight when the animals were killed was $1670 \pm 165 \mathrm{~g}$ in the control birds, $1725 \pm 196 \mathrm{~g}$ in the LD, $1619 \pm 204 \mathrm{~g}$ in the ID and $1720 \pm 251 \mathrm{~g}$ in the HD birds.

\section{Shell quality}

Egg characteristics and eggshell data from the first measuring period (week 32) are given in Table 2. The eggs from

Table 3 Effects of embryonic exposure to $\mathrm{E}_{2}$ on egg and eggshell characteristics, mean values \pm S.D. (second laying period at 46 weeks of age).

\begin{tabular}{|c|c|c|c|c|}
\hline Variable & Control $^{\mathrm{a}}$ & $\mathbf{L D}^{\mathrm{b}}$ & $I^{C}$ & $H^{d}{ }^{d}$ \\
\hline Shell thickness (mm) & $0.35 \pm 0.02$ & $0.34 \pm 0.02$ & $0.34 \pm 0.03$ & $0.32 \pm 0.02 *$ \\
\hline Shell deformation $(\mu \mathrm{m})$ & $2.18 \pm 0.21$ & $2.29 \pm 0.26$ & $2.32 \pm 0.70$ & $2.62 \pm 0.41 *$ \\
\hline Shell weight (g) & $5.33 \pm 0.38$ & $5.08 \pm 0.22$ & $5.20 \pm 0.64$ & $4.92 \pm 0.56$ \\
\hline Egg weight (g) & $57.2 \pm 2.8$ & $56.2 \pm 3.2$ & $57.0 \pm 3.9$ & $55.8 \pm 4.0$ \\
\hline Egg length (mm) & $58.2 \pm 1.2$ & $57.1 \pm 1.1$ & $56.8 \pm 3.9$ & $56.9 \pm 1.6$ \\
\hline Egg width (mm) & $42.1 \pm 0.9$ & $42.0 \pm 0.9$ & $42.5 \pm 0.9$ & $42.0 \pm 1.2$ \\
\hline
\end{tabular}

* Significantly different from controls $(P<0.05)$.

${ }^{a} n=10$ birds. Total number of eggs $=38$.

${ }^{\mathrm{b}} n=9$ birds. Total number of eggs $=37$.

${ }^{c} n=15$ birds. Total number of eggs $=57$.

${ }^{\mathrm{d}} n=9$ birds. Total number of eggs $=36$. 
the HD females had significantly thinner shells compared with the control eggs $(P=0.024)$. In addition, shell weight and shell strength were significantly reduced in the HD eggs ( $P=0.039$ and $P=0.017$ respectively). In the second measuring period (week 46; Table 3), shell thickness and shell strength remained significantly reduced in the HD eggs compared with the controls $(P=0.016$ and $P=0.008$ respectively). Egg characteristics (weight, length, width) did not differ between treatments in any of the two measuring periods.

\section{Egg production, gross morphology and histology}

Egg production of the $\mathrm{EE}_{2}$-exposed females did not differ significantly from that of the control females. The average total egg production per hen by week 47 ( \pm s.D.) was $126 \pm 14$ in the control group, $134 \pm 14$ in the LD group, $126 \pm 14$ in the ID group and $118 \pm 26$ in the HD group. No anatomical alterations in the oviducts were observed in the $\mathrm{EE}_{2}$-exposed birds compared with the controls. At the time when the animals were killed, the average length of the left oviduct was $54 \pm 2 \mathrm{~cm}$ in the control group, $51 \pm 2 \mathrm{~cm}$ in the LD group, $56 \pm 5 \mathrm{~cm}$ in the ID group and $47 \pm 12 \mathrm{~cm}$ in the HD group. All regions of the oviduct were examined by light microscopy. No apparent histological alterations were observed in infundibulum, magnum, isthmus or UVJ in the $\mathrm{EE}_{2}$-exposed birds compared with the controls. In the shell gland, however, an alteration in the number of capillaries was indicated. As revealed by image analysis, the HD birds showed a reduced total number of capillaries in the shell gland, $232 \pm 57 / \mathrm{mm}^{2}$ compared with $280 \pm 57 / \mathrm{mm}^{2}$ in the controls $(P<0.0001)$.

\section{CA localization}

CA localization was investigated in all regions of the oviduct (infundibulum, magnum, isthmus, UVJ and shell gland) in five birds per treatment group. Apparent differences in CA activity between treatment groups were found only in the shell gland capillaries. The shell gland was therefore investigated in all birds; in total, ten controls, nine LD, fifteen ID and nine HD birds. The distribution of CA in the infundibulum and UVJ was in agreement with previous findings (Holm et al. 1996). CA was also expressed in the magnum and the isthmus (see below).

\section{Shell gland}

The surface epithelium was unstained in all birds regardless of treatment. In the control birds, most tubular gland cells showed a weak staining of the lateral cell membranes and occasionally weakly stained cell nuclei (Fig. 1a). A few of the treated birds had patches of tubular gland cells with stained membranes mixed with unstained glands. Any difference between treated and control birds was subtle and not dose related. Cell nuclei were generally unstained in treated birds.

In all control birds, the capillary endothelium showed intense membrane-bound staining (Fig. 1a). In the LD and ID birds, capillary staining was similar to that of the controls. In the HD birds, the frequency of stained capillaries was lower than in the control birds. As revealed by image analysis, the frequency of stained capillaries was only $11 \%$ in the HD group (Fig. 1 b) compared with $52 \%$ in the controls $(P<0.0001)$.

\section{Magnum and isthmus}

The localization of CA activity in magnum and isthmus has not, to our knowledge, been described previously. A brief description is therefore included. In both regions, a majority of the surface epithelial cells showed moderately stained basolateral membranes (Fig. 2). Occasionally weak staining was observed in cell nuclei. In the tubular glands, most of the nuclei were stained. Staining of lateral cell membranes was found in small patches of glands which were mixed with unstained glands. The staining of
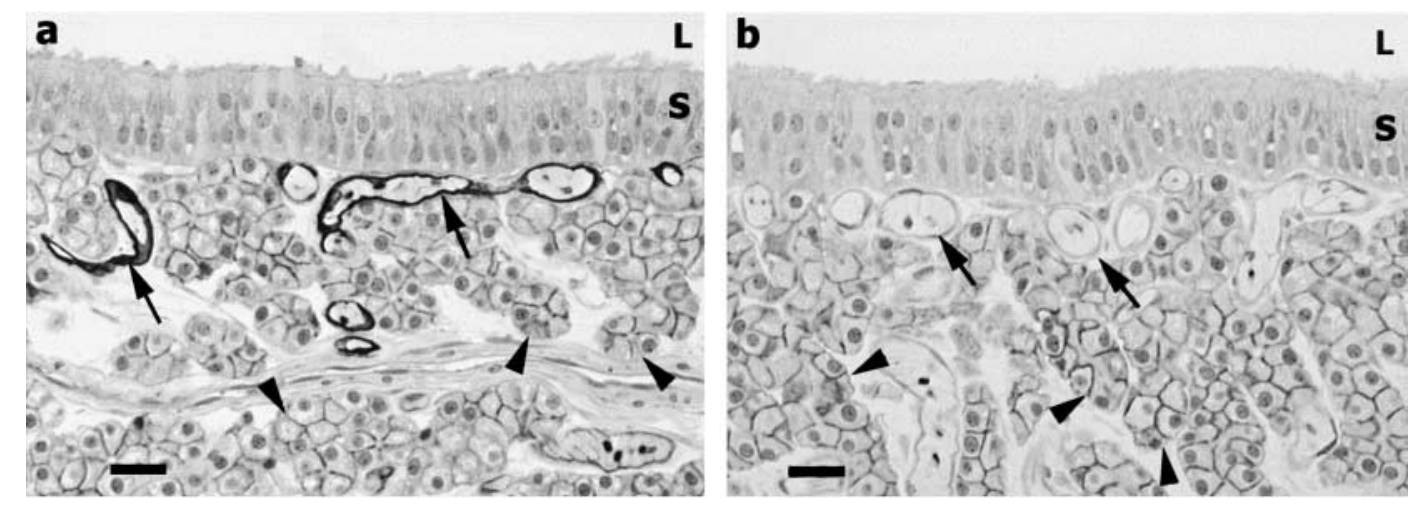

Figure 1 (a) Shell gland from a control hen. Black staining showing active CA in capillary endothelial cells (arrows) and lower activity in the lateral membranes of tubular gland cells (arrowheads). The surface epithelium (S) is unstained. (b) Shell gland from a hen treated in ovo with $20 \mathrm{ng}$ $\mathrm{EE}_{2} / \mathrm{g}$ egg. Weak staining for CA is seen in the lateral membranes of the tubular gland cells (arrowheads). Capillaries (arrows) and surface epithelium (S) are unstained. Nuclei of some erythrocytes show staining in shell gland both from (a) control and (b) $\mathrm{EE}_{2}$-exposed birds. $\mathrm{L}=$ lumen. Weak azure blue counterstain. Bar $=20 \mu \mathrm{m}$. 


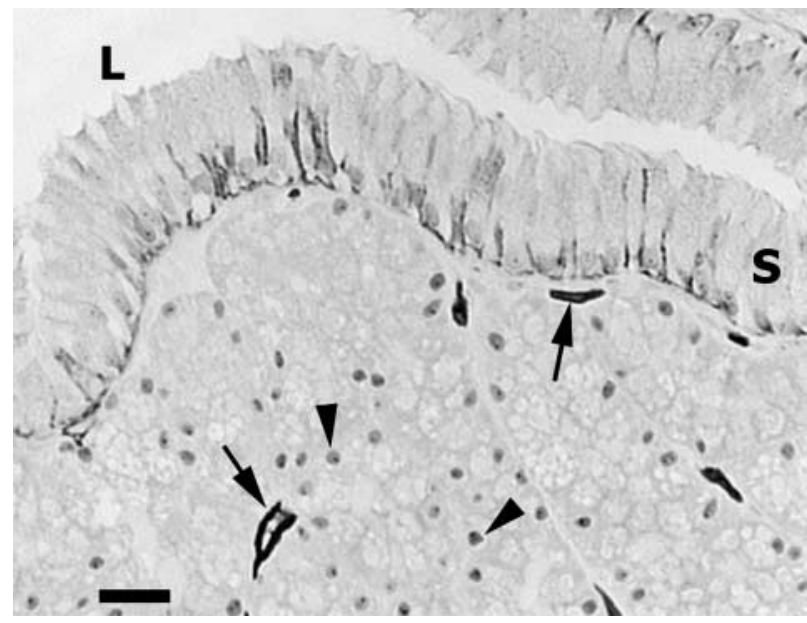

Figure 2 Magnum from a control hen. Staining for CA is found in capillary endothelial cells (arrows) and basolateral cell membranes of surface epithelial cells (S). Note also the stained nuclei of glandular cells (arrowheads). $\mathrm{L}=$ lumen. Weak azure blue counterstain. Bar $=20 \mu \mathrm{m}$.

both surface epithelium and tubular glands was generally stronger in the magnum than in the isthmus. In both regions, the capillaries showed intense membrane-bound staining of the endothelial cells.

\section{Discussion}

The mechanism for contaminant-induced eggshell thinning in wild birds is still not known, although it is generally assumed that it results from exposure of the adult laying female. Here, we have concluded that eggshell thinning can be caused by developmental exposure to oestrogen. Excretion into the yolk is an important route of elimination of lipophilic environmental pollutants in birds.

The study was designed to investigate whether eggshell thinning can reflect a functional and/or structural malformation in the shell gland of the domestic hen. This species is considered insensitive to DDE-induced eggshell thinning in conventional feeding experiments (Cooke 1973). Our results have shown that embryonic exposure to the xeno-oestrogen $\mathrm{EE}_{2}$ in the domestic hen caused production of eggs with reduced shell thickness and strength. In addition, the number of capillaries in the shell gland was reduced in treated birds and fewer of the capillaries showed CA activity. These results support our hypothesis that eggshell thinning can originate from a developmental effect in the shell gland caused by embryonic exposure to oestrogen. To our knowledge, the present study is the first to show that eggshell thinning can be a developmentally induced effect. However, shell-less and soft-shelled eggs have been reported earlier in quail following embryonic exposure to 2-(2-chlorophenyl)-2-(4-chlorophenyl)-1,1,1trichloroethane $\left(o, p^{\prime}\right.$-DDT) at a very high dose (about
$400 \mathrm{mg} / \mathrm{kg}$ ) that also reduced the number of ovipositions (Bryan et al. 1989).

Inhibition of shell gland CA was early proposed as a mechanism for eggshell thinning in wild birds (Anderson et al. 1969, Bitman et al. 1970, Peakall 1970), because administration of CA inhibitors to laying hens results in thin-shelled eggs (Benesch et al. 1944, Gutowska \& Mitchell 1945, Lundholm 1990). The present study has shown that the most pronounced shell gland CA activity resides in the capillary endothelium in the domestic hen. In the $\mathrm{EE}_{2}$-treated $\mathrm{HD}$ birds, both the reduced endothelial CA activity and the decreased number of capillaries in the shell gland mucosa may have negative consequences on eggshell formation by reducing the availability of calcium and carbonate ions. The carbonate ion needed for shell formation is supplied consequent to hydration of $\mathrm{CO}_{2}$ to $\mathrm{HCO}_{3}^{-}$in a process catalysed by CA. CA is present in the glandular cell membranes as well as in capillaries and the $\mathrm{CO}_{2}$ is supplied via the blood plasma and cellular metabolism. Thus, a reduced $\mathrm{CO}_{2}$ diffusion, as a result of a decreased amount of CA in the capillaries in treated birds, could therefore reduce $\mathrm{HCO}_{3}^{-}$transfer to the shell gland lumen. Capillary CA may also influence the microcirculation by mediating changes in extra- and intracellular $\mathrm{pH}$ according to a recent study on rat retina (Reber et al. 2003). Large amounts of calcium are transported by the blood to the shell gland, and blood flow in the shell gland increases significantly during shell formation (reviewed in Johnson 2000). Altered microcirculation and/or a reduced number of capillaries in the exposed birds may therefore reduce the amount of calcium available for shell formation. In addition, impaired transport or reduced concentration of $\mathrm{HCO}_{3}^{-}$ions may also reduce the availability of $\mathrm{Ca}^{2+}$ since transport of these two ions through the shell gland mucosa is, to some extent, coupled (Pearson \& Goldner 1974, Eastin \& Spaziani 1978).

In the present study, we have found that embryonic oestrogen exposure subsequently caused eggshell thinning and that this effect persisted at least over a 14-week laying period. We also found that embryonic $\mathrm{EE}_{2}$ exposure induced persistent effects in quail. Altered shell gland morphology and CA distribution (Berg et al. 2001, Holm et al. 2001) persisted after moult, i.e. after regression and subsequent regeneration of the oviduct (C Berg, L Holm, I Brandt, B Brunström \& Y Ridderstråle, unpublished observations). This implies that wild birds exposed to estrogen-like pollutants as embryos may produce eggs with impaired shell quality throughout their lives. Indeed, a developmental effect may explain why old females of Baltic white-tailed sea eagles (Haliaeetus albicilla) continue to produce eggs with poor shell quality although the levels of persistant pollutants have declined considerably (Helander 1994, Helander et al. 2002). We assessed shell strength by measuring deformation of the eggshell under an applied weight. The decreased resistance to deformation found consequent to $\mathrm{EE}_{2}$ exposure in this study may have been caused by the reduced shell thickness, but 
also by changes in shell porosity, shell membrane quality and shell matrix composition (Örberg 1990, Lavelin et al. 2000). Further studies will be conducted to characterize changes in shell structure following embryonic $E_{2}$ exposure.

The shell gland was the only region in the oviduct showing an altered CA-staining pattern following in ovo exposure to $E_{2}$ in the domestic hen. Embryonic exposure to $20 \mathrm{ng} \mathrm{EE}_{2} / \mathrm{g}$ egg also caused disrupted CA localization in the shell gland in quail. In quail, CA activity was induced in the surface epithelium whereas it was reduced in the subepithelial glands in the shell gland (Holm et al. 2001). Unlike the domestic hen, CA activity of capillary endothelial cells was not detected in quail. In addition to these findings in birds, little is known about hormonally induced developmental reprogramming of CA in the sex organs in different species. It is therefore a notable observation that the CA 2 gene is down-regulated in mouse testis following neonatal exposure to the synthetic oestrogen diethylstilboestrol (Adachi et al. 2004).

In the present study, we observed no anatomical malformations in the chicken oviducts like those observed in adult quail oviducts following embryonic exposure to $20 \mathrm{ng} \mathrm{EE}_{2} / \mathrm{g}$ egg (Berg et al. 2001). In addition, egg production was unaffected in the present study, while quail exposed to $7 \mathrm{ng} \mathrm{EE}_{2} / \mathrm{g}$ egg as embryos failed to lay eggs as adults (unpublished results), probably due to malformation of their oviducts. Furthermore, as shown in studies with diethylstilboestrol, an approximately 25 times higher dose was required to cause Müllerian duct (embryonic oviduct) malformations in chicken embryos compared with quail embryos (Berg et al. 1999, Berg 2000). Taken together, these data imply that oviduct development in quail is more sensitive than in chicken with respect to oestrogenic effects on structure and function. An explanation for the difference between quail and chicken with regard to oestrogen-induced effects on CA may be an interspecies variation in the hormonal regulation of CA activity in the oviduct as observed among mammals. In the rabbit endometrium, progesterone increases CA activity and oestrogen inhibits this effect (Hodgen \& Falk 1971), while these hormones have opposite effects in the mouse (Maren 1967).

In conclusion, we have shown that eggshell thinning and a reduction in CA activity in shell gland capillaries are induced by embryonic oestrogen exposure in the domestic hen. These findings strengthen our hypothesis that eggshell thinning in birds can reflect a functional and structural malformation induced during the embryonic stage. Furthermore, the results suggest that CA is involved in the mode of action for an oestrogen-induced developmental effect on the shell gland. This study highlights the importance of exposure during critical organizational periods when studying endpoints related to the reproductive system.

\section{Acknowledgements}

The authors are grateful to the late Ingrid Wennerberg for expert technical assistance. This study was supported by the Swedish Research Council for Environment, Agricultural Sciences and Spatial Planning (Formas) and Oscar and Lilli Lamm's Foundation.

\section{References}

Adachi T, Koh K-B, Tainaka H, Matsuno Y, Ono Y, Sakurai K, Fukata H, Iguchi T, Komiyama M \& Mori C 2004 Toxicogenomic difference between diethylstilbestrol and 17B-estradiol in mouse testicular gene expression by neonatal exposure. Molecular Reproduction and Development 67 19-25.

Anderson DW, Hickey JJ, Risebrough RW, Hughes DF \& Christensen RE 1969 Significance of chlorinated hydrocarbon residues to breeding pelicans and cormorants. The Canadian Field-Naturalist $8391-112$.

Benesch R, Barron NS \& Mawson CA 1944 Carbonic anhydrase, sulphonamides and shell formation in the domestic fowl. Nature 153 138-139.

Berg C 2000 Environmental Pollutants and the Reproductive System in Birds: Developmental Effects of Estrogenic Compounds. Comprehensive Summaries of Uppsala Dissertations from the Faculty of Science and Technology; 565. Uppsala University, Sweden.

Berg C, Halldin K, Fridolfsson A-K, Brandt I \& Brunström B 1999 The avian egg as a test system for endocrine disrupters: effects of diethylstilbestrol and ethynylestradiol on sex organ development. Science of the Total Environment 233 57-66.

Berg C, Holm L, Brandt I \& Brunström B 2001 Anatomical and histological changes in the oviducts of Japanese quail after embryonic exposure to ethynyloestradiol. Reproduction 121 155-165.

Bitman J, Cecil HC \& Fries GF 1970 DDT-induced inhibition of avian shell gland carbonic anhydrase: a mechanism for thin eggshells. Science 168 594-596.

Brunström B \& Örberg J 1982 A method for studying embryotoxicity of lipophilic substances experimentally introduced into hens' eggs. Ambio 11 209-211.

Brunström B \& Darnerud PO 1983 Toxicity and distribution in chick embryos of 3,3',4,4'-tetrachlorobiphenyl injected into the eggs. Toxicology 27 103-110.

Bryan TE, Gildersleeve RP \& Wiard RP 1989 Exposure of Japanese quail embryos to o, $p^{\prime}$-DDT has long-term effects on reproductive behaviours, hematology, and feather morphology. Teratology 39 525-535.

Chegwidden WR \& Carter ND 2000 Introduction to the carbonic anhydrases. In The Carbonic Anhydrases: New Horizons, pp 13-28. Eds WR Chegwidden, ND Carter \& YH Edwards. Berlin: Birkhäuser Verlag.

Cooke AS 1973 Shell thinning in avian eggs by environmental pollutants. Environmental Pollution 4 85-152.

Eastin WC \& Spaziani E 1978 On the mechanism of calcium secretion in the avian shell gland (uterus). Biology of Reproduction 19 505-518.

Faber RA \& Hickey JJ 1973 Eggshell thinning, chlorinated hydrocarbons and mercury in inland aquatic bird eggs, 1969 and 1970. Pesticide Monitoring Journal 7 27-36.

Gutowska MS \& Mitchell CA 1945 Carbonic anhydrase in the calcification of the egg shell. Poultry Science 24 159-167.

Hamilton RMG 1982 Methods and factors that affect the measurement of egg shell quality. Poultry Science $612022-2039$.

Helander B 1994 Productivity in relation to residue levels of DDE in the eggs of white-tailed sea eagles Haliaeetus albicilla. In Raptor Conservation Today, pp 735-738. Eds B-U Meyburg \& RD Chancellor. Berlin: WWGBP/Pica Press.

Helander B, Olsson A, Bignert A, Asplund L \& Litzén K 2002 The role of DDE, PCB, coplanar PCB and eggshell parameters for 
reproduction in the white-tailed sea eagle (Haliaeetus albicilla) in Sweden. Ambio 31 386-403.

Hickey JJ \& Anderson DW 1968 Chlorinated hydrocarbons and eggshell changes in raptorial and fish-eating birds. Science $\mathbf{1 6 2}$ $271-273$.

Hodgen GD \& Falk RJ 1971 Estrogen and progesterone regulation of carbonic anhydrase isoenzymes in guinea pig and rabbit uterus. Endocrinology 89 859-864.

Holm L, Ridderstråle Y \& Knutsson P-G 1996 Localisation of carbonic anhydrase in the sperm storing regions of the domestic hen oviduct. Acta Anatomica 156 253-260.

Holm L, Berg C, Brunström B, Ridderstråle Y \& Brandt I 2001 Disrupted carbonic anhydrase distribution in the avian shell gland following in ovo exposure to estrogen. Archives of Toxicology 75 $362-368$.

Johnson AL 2000 Reproduction in the female. In Sturkie's Avian Physiology, pp 569-591. Ed. CG Whitton. San Diego: Academic Press.

Lavelin I, Meiri N \& Pines M 2000 New insight in eggshell formation. Poultry Science 79 1014-1017.

Lundholm CE 1990 The eggshell thinning action of acetazolamide; relation to the binding of calcium and carbonic anhydrase activity of shell gland homogenate. Comparative Biochemistry and Physiology 95C 85-89.

Lundholm CE 1993 Inhibition of prostaglandin synthesis in eggshell gland mucosa as a mechanism for $p, p^{\prime}$-DDE-induced eggshell thinning in birds - a comparison of ducks and domestic fowls. Comparative Biochemistry and Physiology 106C 389-394.

Lundholm CE 1997 DDE-induced eggshell thinning in birds: effects of $\mathrm{p}, \mathrm{p}^{\prime}$-DDE on the calcium and prostaglandin metabolism of the eggshell gland. Comparative Biochemistry and Physiology 188C $113-128$.
Maren TH 1967 Carbonic hydrase: chemistry, physiology and inhibition. Physiological Reviews 47 595-781.

Örberg J 1990 Relationship between the shell membrane-shell bond and shell deformation in hen's eggs. British Poultry Science 31 249-254.

Peakall DB 1970 p,p'-DDT: effects on calium metabolism and concentration of estradiol in the blood. Science 163 592-594.

Pearson TW \& Goldner AM 1974 Calcium transport across the avian uterus II. Effects of inhibitors and nitrogen. American Journal of Physiology 227 465-468.

Ratcliffe DA 1967 Decrease in eggshell weight in certain birds of prey. Nature 215 208-210.

Ratcliffe DA 1970 Changes attributable to pesticides in egg breakage frequency and egg shell thickness in some British birds. Journal of Applied Ecology 7 68-115.

Reber F, Gersch U \& Funk R 2003 Blockers of carbonic anhydrase can cause increase of retinal capillary diameter, decrease of extracellular and increase of intracellular $\mathrm{pH}$ in rat retinal organ culture. Graefe's Archive for Clinical and Experimental Ophthalmology 241 140-148.

Ridderstråle Y 1976 Intracellular localization of carbonic anhydrase in the frog nephron. Acta Physiologica Scandinavica 98 465-469.

Ridderstråle Y 1991 Localization of carbonic anhydrase by chemical reactions. In The Carbonic Anhydrases. Cellular Physiology and Molecular Genetics, pp 133-144. Eds SJ Dodgson, RE Tashian, G Gros \& ND Carter. New York and London: Plenum Press.

Received 23 February 2004

First decision 29 April 2004

Accepted 24 May 2004 